\title{
RESISTÊNCIA E REPRESENTAÇÕES DA PROSTITUIÇÃO NA OBRA DE PLÍNIO MARCOS
}

\author{
Gabriel Silveira Martins ${ }^{1}$ \\ Luciana Paiva Coronel ${ }^{2}$
}

\begin{abstract}
Resumo: A produção literária de Plínio Marcos foi marcada por forte cunho social. Em suas peças, contos e crônicas, o autor representou cenários e personagens socialmente marginalizados, tais como prostitutas, homossexuais e criminosos. Frequentemente, apontou a condição degradante e violenta da vida desses sujeitos e denunciou a negligência do Estado opressor para com essa parcela da população - o que garantiu ao autor severa perseguição pela censura no período da ditadura militar. Neste trabalho, pretendemos apresentar a obra de Plínio Marcos como um ato de resistência, através da análise da peça O abajur lilás (1969). Nosso objetivo é identificar quais representações do tema prostituição estão presentes no texto, com especial enfoque às personagens femininas, tentando perceber se tais personagens encaixam-se no binarismo "sagrada x profana" discutido por Moreira (2007) e nos conceitos discutidos por Alves (2002) e Eble (2011). A partir das falas das personagens e das relações que elas estabelecem, observaremos que essas representações, na peça aqui analisada, não são construídas através de estereótipos e de exotismo, limites da representação propostos por Gonzaga (1981) que poderiam questionar o caráter de contestação de uma obra dita "marginal".
\end{abstract}

Palavras-chave: Literatura marginal. Representação. Prostituição.

Abstract: The literary works of Plínio Marcos were always known as carriers of a strong social tone. In his plays, short stories and chronicles the author represented settings and characters that are socially marginalized, such as prostitutes, homosexuals and criminals. He frequently pointed out how degrading and violent were the lives of these subjects and denounced the government's negligence towards these people - what resulted in a severe persecution by the censorship of the military dictatorship period. In this essay, we intend to present Plínio Marcos' literary works as a resistance act, by analyzing the playwright $O$ abajur lilás(1969). Our objective is to identify which representations of the prostitution theme are present in the text, focusing on the female characters and identifying if they fit the binarism "sacred x profane" brought by Moreira (2007), taking, also, into account the concepts brought by Alves (2002) and Eble (2011). Through the analysis of these character's speech and the relations they establish, we will observe that in this playwright the characters are not built with the use of stereotypes or exotism, what is assumed by Gonzaga (1981) as being the limits of representation that could question the contesting nature of a literary work identified as "marginal".

Keywords: Marginal literature. Representation. Prostitution.

\footnotetext{
${ }^{1}$ Graduando em Letras - Português e Inglês, pela Universidade Federal do Rio Grande - FURG.

${ }^{2}$ Doutora em Literatura Brasileira pela Universidade de São Paulo -USP e coordenadora do projeto de pesquisa "Vozes marginais na literatura brasileira dos anos 60 ao presente".
} 


\section{Introdução}

A condição de "marginal" dada a muitos autores e obras literárias, em dado tempo e contexto, deve-se a diversos fatores; dentre os quais a adoção de personagens que representem sujeitos que, numa certa realidade histórica e cultural, não sejam vistos como desejados ou pertencentes àquela sociedade, sendo mesmo repelidos e renegados por esta. O conceito de "sujeito marginalizado" é, portanto, bastante amplo, podendo variar conforme a ótica adotada, abarcando figuras como presidiários, usuários de drogas, homossexuais e travestis, ou mesmo operários, imigrantes ou mulheres.

A despeito da multiplicidade de sujeitos que podem ser considerados à margem, o que há em comum na maioria dos casos é o fato de que, ao colocar no centro de suas narrativas personagens que representam esses sujeitos, normalmente excluídos da literatura dita "oficial", os então chamados autores marginais geralmente o fazem como um ato político, de protesto e contestação. Através de uma obra literária, tenta-se dar voz a sujeitos e comunidades a quem, fora da ficção, tem sua voz silenciada e seus direitos negligenciados. $O$ tom de denúncia é recorrente em muitas dessas obras.

Entretanto, como aponta Gonzaga (1981, p. 152), pode-se pensar em dois problemas na representação desses sujeitos na literatura marginal. O primeiro é o fator da apropriação e da autenticidade dessas representações, uma vez que é possível que o contexto descrito na obra não seja parte da realidade do autor - com que autoridade ele se apropriaria da fala do outro? Entendemos que essa problematização possa ser resolvida a partir das discussões sobre testemunho propostas por Salgueiro (2012, p. 284), ao nos questionarmos até que ponto o pertencimento ou não de um autor desqualifica a caracterização e a denúncia de certo problema social.

O segundo problema - a partir do qual desenvolvemos este trabalho apontado por Gonzaga é o que chamamos aqui de "estereotipação do sujeito": "(...) ao escrever sobre as camadas marginalizadas, poucos vencem a tentação do sentimentalismo ou do sectarismo ou mesmo do escatológico" (GONZAGA, 1981, p. 152). Assim, haveria um "risco" de se limitar a representação desses sujeitos como simples vítimas, estereótipos (reduzidos a características do senso-comum) ou até 
mesmo como "criaturas exóticas", o que entendemos como um empecilho à função de denúncia que essas obras assumem.

A partir do estudo da obra de Plínio Marcos (1935 - 1999), nosso objetivo, neste trabalho, é observar como o segundo "problema" da representação na literatura marginal, conforme Gonzaga, é resolvido em O abajur lilás (1969), peça que enfoca as relações de exploração e poder em um prostíbulo. Buscamos analisar o perfil das personagens, a partir das afirmações que fazem sobre si mesmas. Ainda, levamos em consideração também suporte teórico sobre a representação de mulheres e de prostitutas na literatura canônica brasileira, tentando entender se há alguma diferença entre as representações recorrentes na dita "literatura de elite" e na obra de Plínio Marcos.

\section{O abajur lilás e a contestação na obra de Plínio Marcos}

Desde a sua primeira peça, Barrela (1959), Plínio Marcos ganhou a alcunha de "escritor maldito", rótulo do qual se apoderou também como estratégia para promover sua obra (MOTA, 2015, p. 329). Nascido em Santos, conviveu desde cedo com personagens locais, presentes na zona portuária, como ladrões, prostitutas e malandros. O apelo popular de sua obra, na qual representa as vidas de muitos daqueles sujeitos, provém também das características pessoais do autor, que chegou a exercer profissões como a de palhaço e a de camelô (MENDES, 2009).

Utilizando linguagem popular, carregada de palavrões, as peças e crônicas de Plínio apresentavam um tom crítico e de denúncia das condições degradantes que aqueles sujeitos marginalizados enfrentavam e da negligência do Estado com aqueles seres humanos. Assim, sua obra também pode ser vista como um ato de resistência, como tema e forma (BOSI, 1996, p. 18), intrínseca e extrínseca ao texto - a própria escolha do gênero dramático permitiu uma veiculação maior das mensagens do autor, que também atuou em algumas montagens de seus textos. Muitas de suas peças foram levadas para escolas e também há registro de apresentações para públicos de operários.

Entretanto, Plínio Marcos pagou, desde cedo, o preço pelo tom de suas peças: Barrela foi censurada logo em seu lançamento e só pode ser encenada novamente após longos 21 anos. A situação agravou-se a partir do Golpe Militar de 1964, uma vez que os novos trabalhos de Plínio mantinham tanto a linguagem 
quanto o teor de denúncia à repressão. $O$ autor foi severamente perseguido pela censura, sendo suas peças proibidas de serem encenadas, e os textos proibidos de serem comercializados, o que obrigou o autor a buscar outros meios de sobreviver, mas sem abandonar a literatura.

Fora o aspecto político, é recorrente nas peças de Plínio Marcos uma problematização sobre as questões de gênero e de sexualidade. Em Barrela (1959) e A mancha roxa (1988) há conflitos sobre construção das masculinidades e feminilidades, respectivamente; em Quando as máquinas param (1971), a tensão se constrói em torno da disputa de poder entre marido e mulher e da legitimação de seus papéis culturais. Já em Navalha na carne (1968), esses temas todos aparecem concentrados. Apesar de não ser o foco deste trabalho promover uma leitura de $O$ abajur lilás sob a ótica do gênero, ao problematizarmos a representação de sujeitos - mulheres - socialmente e historicamente marginalizados, não podemos perder de vista essa discussão.

Escrita em 1969, ano da aplicação do Ato Institucional no 5, O abajur lilás foi imediatamente proibida em todo o país. $O$ enredo da peça traz as prostitutas Dilma e Célia, que dividem um quarto na propriedade de Giro, homossexual e cafetão que explora o trabalho delas através de ameaças e manipulações. Com a chegada de uma nova prostituta ao quarto, Leninha, e com o aparecimento de um abajur e de outros objetos quebrados, a peça tem andamento até seu ápice na cena final, em que Giro, com a ajuda do capanga Osvaldo, prende as três mulheres e as tortura, a fim de descobrir quem havia quebrado os objetos. Após arrancar uma confissão, uma das moças é friamente assassinada.

Fica claro o porquê de este texto ter sido censurado, logo da sua publicação. Plínio Marcos traz novamente um sujeito socialmente marginalizado - a prostituta para o centro do palco, com o objetivo de denunciar o degradante estado de vida daqueles personagens. Como se isso e a linguagem empregada (chula) não fossem incômodos o bastante para a censura, a cena final da peça recria uma sessão de tortura muito similar às que ocorriam nos porões do DOI-CODI, por exemplo, empregando instrumentos e técnicas como alicate e pau-de-arara. Trata-se de uma denúncia direta, levemente disfarçada sob o enredo da peça, da crueldade empregada pelos militares no período. A execução final e a relação entre as personagens femininas e o cafetão Giro podem ser entendidas como metáforas das 
relações de opressão do período, em que as prostitutas representariam o povo, e Giro, o regime militar - relação semelhante, em outra peça de Plínio, é constatada por Soares (2010, p. 88). Como se vê, trata-se de uma obra crítica e de mais de uma leitura, razões que nos levaram a escolhê-la como objeto de estudo.

\section{Análise das personagens}

Vários trabalhos dedicam-se a analisar as representações de profissionais do sexo em obras literárias dos mais variados contextos. Aqui, tomamos como ponto de partida a análise feita por Moreira (2007, p. 237). A autora propõe uma leitura dessas representações, na literatura brasileira do século $\mathrm{XX}$, através do conceito de "mundo profano" (o espaço habitado pela personagem prostituta) e "mundo sagrado" (o espaço social, regulamentado pela moralidade), tomando a personagem prostituta como ponto de integração entre esses dois mundos. Moreira faz uma breve recapitulação histórica do imaginário sobre esses sujeitos, vistos como sagrados na Antiguidade (sacerdotisas que promoviam o contato com os deuses através do ato sexual), até a contemporaneidade, em que o ideal de sacralização dissipou-se completamente e foi substituído "pelo universo erótico, misterioso e profanado da prostituta" (MOREIRA, 2007, p. 239). A autora continua:

Nas ficções, o universo da prostituta é narrado, de forma recorrente, como o espaço do profano, da luxúria, do desregramento moral e social, por influência, em parte, de dogmas religiosos, sociais e políticos de aceitação. De acordo com tal perspectiva, ele representa o local do excesso, da farsa e da dissimulação, povoado por seres humanos estranhamente contraditórios, que não se enquadram ao lócus moral e social de prestígio (MOREIRA, 2007, p. 239).

Tomando como base essas e outras reflexões, e observando alguns exemplos citados pela autora - dentre eles Lúcia, personagem de Lucíola, de José de Alencar, entendemos que, embora a personagem prostituta, simbolicamente, integre os mundos sagrado e profano; sob a ótica da representação essas personagens geralmente estão associadas a um polo ou outro: assim, coexistem, nas obras literárias, prostitutas descritas como imorais, devassas e perigosas, junto com personagens plenas de aspectos morais, levadas ao ramo por desventura ou necessidade, "desvirtuadas". É essa dualidade - ou as possibilidades entre um extremo e outro - que buscamos tentar encontrar na peça de Plínio Marcos. 
Os personagens representados em $O$ abajur lilás são representativos de sujeitos que trabalham e vivem no ramo da prostituição, destacando-se o cafetão Giro e as garotas de programa, Célia, Dilma e Leninha. Optou-se, aqui, por analisar estas duas últimas, por entendermos que apresentam traços antagônicos que permitem-nos uma discussão maior sobre como é representada a personagem prostituta, pergunta norteadora de nossa pesquisa. A partir daqui, tentaremos entender em que categorias se inscrevem, ou não, essas personagens, pensando também nos arquétipos discutidos por Alves (2002) sobre a representação da mulher, do Romantismo até a contemporaneidade:

Portanto, a grande maioria de escritores, na ascensão da burguesia, era homens que se empenharam na construção de um modelo de mulher burguesa; na realidade, construíram três tipos de comportamento (modelo): a mulher-anjo, a mulher-sedução (ambas aceitas pela sociedade) e a terceira, a mulher-demônio, a excluída, porque representava a mulher tentação. Esta exclusão que, inicialmente, podia designar a prostituta, no final do século XIX se amplia para, também, designar as mulheres intelectuais e todas aquelas que resistiam a comportar-se conforme o modelo idealizado e aceito pela sociedade burguesa (ALVES, 2002, p. 88).

Em O abajur lilás, Dilma é, pode-se dizer, a personagem central da peça ou, ao menos, a personagem feminina com mais falas e tempo em cena. Notadamente apresenta um forte aspecto moral (talvez mesmo conservador), ligado tanto à recriminação de certas práticas sexuais - enoja-se quando Giro a aconselha a fazer outras posições sexuais com os clientes: "Uma puta nojenta e sem calça. Sou mulher da vida, mas tenho moral. Comigo é aqui. Se o freguês tentar outros babados, mando falar com tu mesmo, que é bicha" (MARCOS, 1969, p. 19) - quanto a certos discursos homofóbicos. Declara que não gosta de ser uma profissional do sexo, o fazendo como única opção para sustentar o filho, que ainda é um bebê. Dilma retoma o pensamento no filho em diversos momentos críticos na peça, quando é obrigada a tomar decisões e justifica o seu não envolvimento na querela entre Célia e Giro, justificando que precisa manter-se no emprego por causa da criança. Mais de uma vez demonstra uma certa preocupação em manter-se de consciência filha em nome do filho; essa sendo, inclusive, uma de suas últimas falas antes de desmaiar na cena de tortura que encerra a peça: "Ai, meu filho! Meu filho! Eu sou limpa! Ai, ai! Limpa..." (MARCOS, 1969, p. 67). 
Das três personagens femininas, Dilma é quem tem a relação mais branda com o cafetão Giro, rebatendo-o apenas quando ele a acusa de algo ou a pressiona. Fala-se que em certa ocasião de doença ele teria cuidado dela (e cobrado por isso) e ao final da peça é a ela a quem ele primeiro pede a identidade do suposto culpado pela destruição no quarto. Mas não se trata de uma relação afetuosa, de forma alguma; tanto por se tratar de uma relação de exploração com base na ameaça e no uso da violência física, quanto pelo asco/repulsa que Dilma sente pelo cafetão. Essa ojeriza está diretamente ligada com uma série de falas que a personagem tem na peça, em que afirma não gostar de homossexuais. Inclusive, mais de uma vez, quando the é mencionado algo sobre Célia ser sua amiga, a personagem parece confundir amizade entre mulheres com homossexualidade feminina, declarando que "quem tem amiga é greluda" (MARCOS, 1969, p. 17) e "quem tem amiga é roçadeira. E eu já te disse que meu negócio é homem" (MARCOS, 1969, p. 18).

Ao tentarmos traçar a personalidade da personagem Dilma com base no que diz sobre si mesma e na sua relação com as demais personagens, percebemos que ela se mostra bastante complexa, e até mesmo contraditória em alguns aspectos. Ao longo de toda a peça, Dilma enfatiza o amor que sente pelo filho, justificando sua neutralidade ou razão para evitar atritos pela dependência que seu filho tem dela, pois é por causa dele que ela enfrenta uma profissão da qual não gosta. Deixa a entender que seu filho é o único com quem tem uma relação de afeto, repudiando amizade com outras pessoas, como Célia. Entretanto, ao ser provocada por Giro com a possibilidade de seu filho ser / tornar-se homossexual um dia, rejeita-o, dizendo "prefiro ver ele morto" (MARCOS, 1969, p. 21). Em um desabafo, a personagem ressalta a preocupação em manter o filho e tentar evitar que ele seja homossexual:

Não é nada disso. Eu tenho meu filho pra criar, entendeu? Tu é tu mesmo. Tanto faz, como tanto fez, Mas essa porrice-louca não dá pra mim. Eu sou meu filho, Tu já pensou se eu entro numa gelada como é que ele fica? Pensa, O coitadinho não sabe de nada. Eu é que tenho que dar as dicas da vida pra ele. Sem mim, ele se dana, Pode até..pode até. . . Sei lá! Pode até virar um veado como esses Giros que andam por aí. Deus me livre! Eu não gosto nem de pensar. Não, não! Eu não gemi no parto pra largar cria solta nesse mundo de coisa ruim. Eu me dano. Me lasco. Me entralho. Mas faço do meu nenê um homem. Não um veado. Ele tem que ser bacana. Daí ele ocupa um lugar. E me ajuda. Aí, sim, a gente, eu e ele, mudamos o resultado do jogo. Já, eu agüento a mão, É preciso, Meu nenê 
precisa, Mas eu vou dando os piás positivos. E dois é mais que um, Eu e ele vamos sair pra melhor. (Pausa) Sem mim, o que ele faz? (MARCOS, 1969, p. 33).

Por fim, ainda que afirme não ser amiga de Célia, Dilma demonstra uma constante preocupação com esta, busca dar-Ihe conselhos e, na quarta cena, pede para que ela e as companheiras de quarto sejam mais unidas. Todos esses traços que formam a personalidade da personagem mostram que ela está longe de ser classificada como uma personagem plana, limitada apenas a sua condição de prostituta, mostrando-se, de fato, complexa como representação humana, com suas fobias e incoerências.

Se Dilma tenta manter-se neutra, evitando conflitos, apegando-se no laço com seu filho e tentando manter uma relação de afeto (embora ela negue) com as demais personagens, Leninha mostra-se decidida e até mesmo manipuladora. A personagem é introduzida apenas na terceira cena, tendo um número menor de falas do que a outra; porém essas falas são muito significativas no que tange à personalidade da personagem e na representação que é por ela feita de uma garota de programa.

Mais nova que as demais, Leninha escolheu ser prostituta - diferente de Dilma, cujo único caminho foi este, algo frequente ao pensarmos na representação desses sujeitos na literatura. Enquanto a mais velha vê com nojo e desprezo esse modo de vida, Leninha optou por estar ali, pois acredita que há opções piores:

CÉLIA - Se tu é sabida, tu devia estar na maré mansa.

LENINHA - E não tou? Entrei nessa porque quis. É mole. Uns dois michês é mais que um mês de trampo legal. $E$ aqui não tem deschavo. Agüentar essa bicha é sopa. Duro é ser babá de filho dos outros pra ganhar uma merda. E o que é pior é que a gente trabalha, trabalha e todo mundo acha que a gente é puta. Então, a ordem é ser puta mesmo. Mas devagar. Sem perereco. Quás-quás-quás não dá camisa a ninguém (MARCOS, 1969, p. 59, grifo nosso).

Trata-se de uma inversão total da ideia, recorrente, da prostituição como "um mal necessário", uma última opção, algo apenas degradante e que corrompe o sujeito, já que a personagem demonstra achar menos honroso trabalhar cuidando de crianças do que dormindo com os clientes. 
A personagem mostra-se desaforada e esperta, fazendo diversas exigências a Giro quando da sua chegada e declarando às demais que sabe como manipulá-lo. Ri à toa e gosta de ler, hábito que provoca estranhamento no novo ambiente:

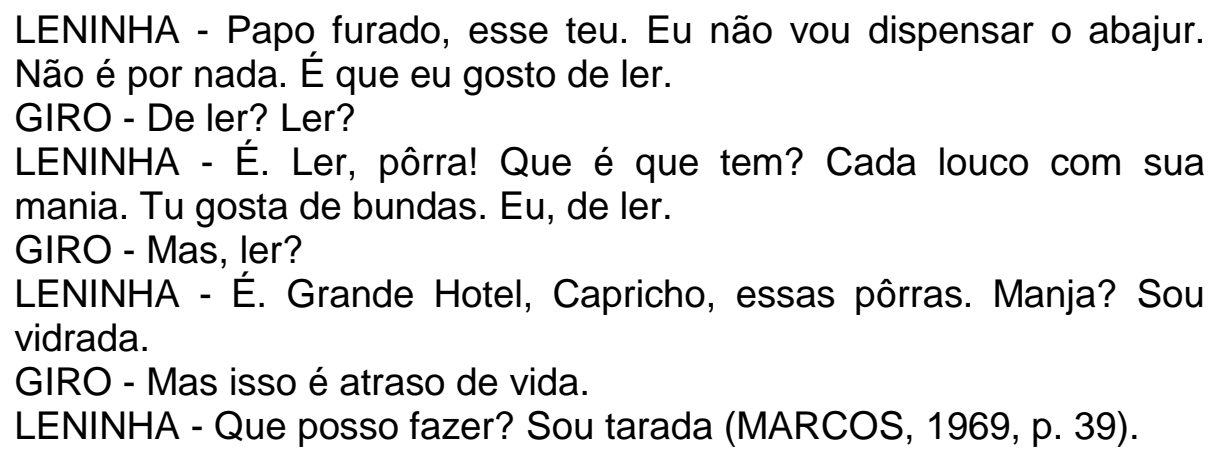

Diferente de Dilma, não apresenta interesse em constituir laços afetivos com ninguém, e, quando questionada, declara odiar os homens. Essa atitude independente e debochada da personagem é criticada por Dilma, que comenta que agia assim até ter seu filho e suas prioridades mudarem. A partir daí podemos pensar com uma maior amplitude na construção da personalidade de Dilma, cuja nova colega seria um reflexo de sua juventude, e a versão atual, o fruto do esforço, da descrença em uma saída e da exploração contínua no prostíbulo.

Eble (2011, p. 1379) faz uma análise dos limites da representação da prostituta na literatura contemporânea, buscando contrastar exemplos encontrados em contos e na música com dados de pesquisas sobre sujeitos reais. O principal paradigma apontado pela autora é a ausência de certos aspectos identitários, como a prostituta que é mãe, esposa, estudante, etc. Ao analisar uma letra de rap, a autora destaca:

a preocupação com os filhos é marcante, trazendo para a música esse lado das relações familiares, tantas vezes negligenciado quando se fala das prostitutas em outras instâncias. Não só é marcante pelo fato de considerar possível que as prostitutas sejam também mães e que tenham todas as preocupações com os filhos como qualquer mulher, mas também porque, a impressão que se tem é que é quase como se os filhos fossem a razão de continuarem vivendo e suportando a vida que levam ou como se os filhos fossem a ponte que ainda Ihes permite vislumbrar alguma honra e dignidade - ao se mostrarem responsáveis com os filhos, elas teriam algum valor afinal (EBLE, 2011, p.1388). 
Assim, embora o objeto de estudo da autora seja uma seleção de textos de produção mais recente, e $O$ abajur lilás seja datado do final dos anos 60 , é possível fazer uma ligação direta entre o que ela aponta e a personagem Dilma, que enfrenta as adversidades e a exploração tendo o filho como sua única motivação e sólido laço afetivo. Essa característica aproxima a personagem (mas não a torna exclusivamente) dos aspectos que compõe o imaginário "sagrado" da prostituta, já discutidos anteriormente. Ao mesmo tempo, Leninha apresenta aspectos que causam estranhamento ao demais personagens - o gosto pela leitura, a opção pela prostituição, a visão não estigmatizada sobre a profissão - e que são comuns a profissionais do sexo reais. Situações que, como aponta Eble, não são comumente representadas na literatura atual, mas que podemos encontrar nesse texto de 1969.

\section{Considerações finais}

As considerações trazidas por Alves (2002) e Moreira (2007) nos mostram que, historicamente, a prostituta foi retratada na literatura como uma categoria ou estereótipo, quase sempre negativa, imoral e exótica. Portanto, não são recorrentes representações que as aproximem de sujeitos comuns, que frequentem outros espaços, que possuam vida social e que tenham desejos e receios outros que não necessariamente relacionados ao mundo dos profissionais do sexo. Já Gonzaga (1981) problematiza que a representação de sujeitos socialmente marginalizados enfrenta um "limite": a possibilidade de se recorrer ao vitimismo ou à estereotipação, o que pode prejudicar o aspecto de contestação que muitas obras da chamada literatura marginal carregam.

A obra do santista Plínio Marcos confunde-se, assim como sua vida pessoal, com seu empenho e luta contra a opressão e a negligência do Estado com sujeitos como presidiários e homossexuais. Dedicou boa parte de sua vida ao teatro e através dele e dos dramas de seus personagens, manifestou suas críticas contra o próprio Regime Militar, o que Ihe custou severa perseguição e muitos trabalhos censurados.

O mesmo aconteceu com $O$ abajur lilás (1969), em que invoca uma cena de tortura no palco, aos moldes do que acontecia então. Entretanto, o destaque da peça talvez seja a construção das personagens femininas, em especial Dilma e Leninha. Com ressalva aos limites que certamente existem, entendemos que essas 
personagens se afastam do puro estereótipo negativo e lascivo da prostituta, tão usual na dita literatura canônica. Ambas as personagens trazem aspectos que as aproximam de sujeitos reais - seres humanos - que não se definem apenas pela profissão que exercem. Essas e outras reflexões, provenientes a partir da leitura do texto de Plínio Marcos, permitem-nos dar início a outras pesquisas sobre a representação de profissionais do sexo na literatura contemporânea, procurando entender quais são essas identidades e de que forma elas são retratadas e/ou silenciadas.

\section{REFERÊNCIAS}

ALVES, Ivia. Imagens da mulher na literatura na modernidade e contemporaneidade. In.: FERREIRA, Sílvia Lúcia, NASCIMENTO, Enilda Rosendo (orgs.). Imagens da mulher na cultura contemporânea. Salvador: NEIM / UFBA, 2002. P. 85 - 98.

BOSI, Alfredo. Literatura e resistência. São Paulo: Companhia das Letras, 2002.

EBLE, Laeticia Jensen. "Escrevendo sua história com neon": representação literária das prostitutas na contemporaneidade. In: Anais do XIV Seminário Nacional Mulher e Literatura / V Seminário Internacional Mulher e Literatura: Brasília, 2011.

GONZAGA, Sérgius. Literatura marginal. In.: FERREIRA, João-Francisco. Crítica literária em nossos dias e literatura marginal. Porto Alegre: Editora da Universidade, UFRGS, 1981. P. 143-153.

MARCOS, Plínio. O abajur lilás / Oração para um pé de chinelo. Editora Parma, 1969.

MENDES, Oswaldo. Bendito maldito: uma biografia de Plínio Marcos. São Paulo: Leya, 2009.

MOREIRA, Ariágda dos Santos. O espaço da prostituta na literatura brasileira do século XX. Caligrama, Belo Horizonte, v.12, pp. 237-250, 2007.

MOTA, Lia Duarte. Plínio Marcos: faces de um personagem marginal. In.: FARIA, Alexandre; PATROCíNIO, Paulo Roberto Tonanido; PENNA, JoãoCamillo (orgs). Modos da margem: figurações da marginalidade na literatura brasileira. Rio de Janeiro: Aeroplano, 2015. P. 326-347.

SALGUEIRO, Wilberth. O que é literatura de testemunho (e considerações em torno de Graciliano Ramos, Alex Polari e André du Rap). Matraga, Rio de Janeiro, v.19, n.31, jul./dez. 2012.

SOARES, Maria de Fátima Bessa. Porta-vozes do poeta maldito: gênero e representação no teatro de Plínio Marcos. Dissertação (Mestrado em Letras) UFMG, Belo Horizonte, 2010. 